\title{
The Significance and Thinking of Translation Teaching in College English Education
}

\author{
Wei Geng \\ School of Foreign Languages, Inner Mongolia University of Science and Technology, Baotou, \\ 014010, China
}

Keywords: English education. Significance. Thinking

\begin{abstract}
Translation teaching plays an essential role in the English education in higher learning in our country. Training university students' translation skills is crucial in the whole English teaching during the colleges and universities period, but translation teaching has always been the weak department in English education. Therefore, we should understand the significance of translation teaching of college English education deeply and improve the university students' translation ability by adopting feasible idea positively so as to promote their comprehensive quality in English.
\end{abstract}

\section{Introduction}

As well as Chinese, college English education has ability requirements in 4 aspects including listening, speaking, reading and writing while translation is the fifth ability in English learning. The English teaching can be improved practically only when listening, speaking, reading, writing and translation are combined with each other. Of source, if we want to learn a foreign language well, we should know how to translate it into native language, which can make the teaching of this foreign language more meaningful. We can see that the significance of translation is very remarkable. But from the point of teaching practice, the current situation of translation teaching of college English education is not optimistic. Teachers must be aware of the significance of translation in English education and teach some specific teaching method about translation.

\section{The Significance of Translation Teaching in English Education of Higher learning}

At first, it can improve the ability of listening, speaking, reading and writing. Translation ability is connected with abilities like listening, speaking, reading and writing. University students can gain a huge amount of language knowledge by utilizing a large number of training of translation between Chinese and English, and through the conversion of the language between Chinese and English during the translation process, the university students can not only be proficient in Chinese thinking, but also consider problems in English thinking skillfully, which can further improve various abilities including listening, speaking, reading and writing. The level of translation ability also influences the information acquisition, thought expression and the correct understanding about the text directly.

Secondly, it can help university students understand some difficult words or phrases correctly, which is very helpful about the understanding of the whole chapter. English teachers always realize during the class that the students are still confused when it takes the teachers a large amount of effort to explain every word or phrase in English. However, if the teachers explain them in native language, then the students will understand it. Then we can see that the explicit explanation of difficulty words and sentences will not disturb the foreign language with native language, instead it is beneficial for the improvement of university students' understanding ability. Translation during teaching process can also check the university students' degree about the understanding and grasp of contents taught so as to find out about irrational points that the university students own. After that, we can act appropriately to the situation and solve the problems. At present, the exercises after a large amount of reading part are objective questions, so that the students can guess the right answer when they have a superficial knowledge about the reading or even can not totally understand it. It has low reliability to decide whether students have correct understanding according to this exercise. Translation mainly 
includes two aspects, understanding and expression, which means that you can conduct correct translation only when you totally understand the contents that you read. During the process of classroom teaching, carrying out some exercises about translation can keep expanding the university students' scope of knowledge so as to intensify their language accomplishment.

Thirdly, it can help university students understand the difference between eastern and western culture. During the process of classroom teaching of college English translation, the sentences translated by many students are not smooth and sometimes, the the words even fails to express the meaning. Some students say that they know every word in the sentence, but still they can not understand the correct meaning of the whole sentence. When it comes to the reason, cultural background plays a very important role. Therefore, translation is not simply a conversion between languages, it also includes a large amount information about nationality and culture. This means that in translation teaching, we should pass a culture reflected by some languages into another culture as much as possible. During the process of classroom teaching, university students can also understand the difference between eastern and western culture, because the translation skills can not compensate for the complicated cultural factors. Therefore, teachers should let students understand comprehensively and deeply about the original language and the target language during the classroom teaching of translation.

Fourthly, it can improve the university students' translation ability. Translation teaching in college English education possesses strong practicability. Under the background that the world's economy tends to integrate, it's difficult for countrymen to understand the world and for the people to understand China without translation. For the university students studying different majors in our country, they not only need to read many professional materials in foreign languages but also need to bear the heavy responsibility of being message sender after graduation. In light of the relevant changes generated by the talent requirements standard from the development of economic development, the internationalization trend of the higher education in our country is becoming more and more remarkable, which puts forward new requirements about the translation ability of the young students in our country's colleges and universities.

\section{The Current Situation of College English Translation Teaching.}

Firstly, the teaching thinking of translation is old-fashioned. The main task of English teaching in institutions of higher learning is to train university students' English application ability. Translation teaching is very crucial as the essential link to train university students' verbal comprehension and expressive ability. However, with the constant emerging of new-type teaching methods such as situational teaching approach and communicative approach in college English classroom teaching, the translation teaching is deserted. At present, the college English teaching emphasizes the training of listening and reading, but ignores the translation teaching which is equally important, which causes the obsolescence and singleness of teaching thought, mode and method. The teaching thought of the English teachers relies on the fixed teaching outline and lacks flexibility. They mainly follow the original teaching mode and put too much emphasis on theoretical explanation. The application of multimedia room in colleges and universities is limited to the teaching of listening and speaking, which makes the translation teaching a part of theoretical teaching. It's bad for the development of the university students' self-regulation of learning.

Secondly, the power of teaching body of English translation is weak. In our country, the outstanding college English teachers are mainly focused on the professional teaching of English while the faculty of English in other majors is feeble. They lack strict and regulated professional training in common and they barely explain the contents about translation due to English textbooks and the limitation of class hours. Sometimes even they explain the part, it's super-facial. Therefore, the construction of English translation faculty in colleges and universities needs to be put on the agenda urgently.

Thirdly, comprehensive cultural quality and language ability of university students are not ideal. In translation practice, discourse is the translation object and the basic unit. Because English and 
Chinese readers live in different cultural environment, so there must be a huge difference in knowledge structure. Therefore, the difference is generated about the understanding and acceptance of the information in discourse. The university students in our country should realize the difference of English and Chinese culture and try to cross the barrier of language. Whether basic skills of language is solid or not is also the important factor that influences the university students' translation ability. Translation work requires the common sense in many aspects mainly including the translator's English and Chinese knowledge in which Chinese knowledge mainly includes grammar, rhetoric and logic and English knowledge includes grammar, rhetoric and logic. At the same time, they should also lay emphasis on absorbing various theoretical knowledge and apply the basic knowledge into translation flexibly. Once the university students' basic skills of language is not solid, it will certainly influence the improvement of their translation ability greatly. Apart from the level of consolidating foundation of cultural environment and basic skills of language, teachers should lead the university students to carry out the translation positively. Whether teachers pay attention to the training of university students' translation ability also influences the increase of their translation ability.

\section{Strengthing the Thought of Translation Teaching in College English Education}

\section{Strengthing the Training of Basic Skills of Translation}

College teaching should emphasize the training of university students' practical ability. The training of basic knowledge focuses on ability cultivation while classroom teaching of English translation is based on basic vocabulary, grammar and syntax. This requires the teachers to let university students remember, utilize flexible words and usage well during the teaching process so that the students can distinguish all the stylistic features owned by the words and expressions. Since many university students' grammar knowledge is weak, then they think that translation from English to Chinese is too easy by translating one by one, while they are totally confused during the process of translation from Chinese to English. Therefore, a main task of English teachers is to intensify the teaching in grammar to let the university students know the structure of sentences. At the same time, translation teaching should also strengthen the training of reading and writing. In college English teaching, listening, speaking, reading, writing and translation are a whole and translation, reading and writing are closely connected. English teachers should emphasizes on training university students' reading habit in order to let them have the ability of reading some simple English reading materials and form their habit of writing. Writing diary and reading notes can enrich their expressive ability in English. Of course, reciting masterpieces is also good for the their cultivation of language sense and increase their interest in English learning, which is beneficial for the English study in the future.

\section{Leading Modern technology to Cooperate with English Translation Teaching}

In light of the popularity of computer and network, the form of information spreading also changes greatly. The efficiency of information spreading gains huge improvement. We should try brand new teaching method by breaking translation teaching away from the traditional mode according to the needs of the age and social development. College English teaching is not set up for non-english college students so it has less class hours compared with English for specific purposes and it takes up a small proposition in translation. Therefore, we should motivate university students' passion of self-learning translation by depending on network, applying the methods including language database, translation software and forum and utilizing interactive teaching methods. We need to take advantage of the computer network and adopt translation theory and translation examples for university students to study in order to compensate for the shortage and weakness in classroom teaching of translation. At the same time, university students should also conduct autonomous learning by utilizing the language database out the school hours because language database can provide a more independent learning environment for the translation teaching in institutions of higher learning. University students can find out their own characteristic and conversion methods of native and foreign language from it. Training university students' consciousness of translation can form their ability of translation strategy gradually. At the same time, university students can also take advantage of machine translation and memory system of translation to provide them enough reference resources, which can help them gain 
more information in shortest time and finish more translation work. Meanwhile, university students can exchange various translation information by using the translation forums and construct information better in the process of interaction with others. Therefore, in this way, the teaching quality and effect can be greatly improved and strengthened.

\section{Realizing the Permeation of Cultural Consciousness}

Translation is based on cross-cultural background and is an language activity of reappearing the contents expressed by another language correctly and completely with one language. It's not only a conversion between two languages, but also a collision between two cultures. Every language has its unique cultural background and bears different cultural characteristics. whether there exist the deficiency of language knowledge and translation skills influences the English translation ability, also the interference of culture plays an important role. Therefore, dealing with cultural difference well is a huge task in college translation teaching. University students know little about the difference between Chinese and western cultures so the cultural study must be added into the class. It has an important function of conditionality in translation through the introduction of history, life, religious belief and etiquette and custom. For university teachers, the merging of culture can guide the university students to understand it deeply and realize the combination of language and cultural teaching and it's also the process of converting knowledge into the development of intercultural communication competence. We can see that college English translation teaching should keep pace with cultural teaching in order to let university students understand the similarities and differences in different languages' structure and culture, improve their sensitiveness to language and culture so as to make the translation accord with the style of original text more.

\section{Promoting the Faculty Construction of English Translation}

The basic of education lies in the teachers. Promoting the faculty construction of college translation is the key point to train the university students' translation ability. All things will be illusory like moon in the water and flowers in the mirror without qualified faculty power. An English teacher who love and understand translation work, possess abundant theory and practical experience of translation can permeate the related translation knowledge in college English teaching, devote him/her to increasing strong interest in English translation, conduct comparable analysis about Chinese and English and the implementation of cultural thought in classroom teaching so as to cultivate the current university students' translation ability. In light of this, we suggest that various administrative departments for education should intensify their efforts in order to conform to the requirements of college English translation teaching better.

\section{Conclusion}

In a word, English is the most popular language around the world. Studying English well can make the learners possess a better future and translation teaching is an integrate part in English teaching. The university students can communicate with foreigners proficiently in English with high ability of English translation. Therefore, teachers and students from institutions of higher learning should act appropriately to the situation based on the deep analysis of the current situation of English translation teaching, adopt reasonable teaching methods and impart them the translation skills so as to make them apply English well.

\section{References}

[1] Lijun, Gunan: The Exploration of How to Strengthern the Translation Teaching in College English Teaching, The Journals in Jiangxi Bluesky University, 2009

[2] Zhang Yiyu: The Consideration about the College Translation Teaching, The Journals in Mongolia Institute of Finance (Comprehensive Vision), 2010(1)

[3] Yin Shaoping: Realizing the Importance of Translatio in College English Teaching form the Students’ Deficiency in Translation Ability, Journal of huaihua university,2010(12). 
[4] Hanxing: The Research of Teaching Strategy in College English Translation, The Journal of Harbin University of Finance,2011(4).

[5] Song Weiwei: The Discussion of Translation Teaching of Vocational English, The Enterprise Herald,2011(18). 